\title{
Desorption properties of BSA and LSZ on carbonate ion-modified apatite
}

\author{
Toru KANNO, ${ }^{\dagger}$ Toru SENDAI, Kiyoshi TADA, Jun-ichi HORIUCHI, Toshiyuki AKAZAWA* and \\ Koji ITABASHI*
}

Department of Biotechnology and Environmental Chemistry, Kitami Institute of Technology, 165 Koen-cho Kitami, Hokkaido 090-8507

*Hokkaido Industrial Research Institute, Nishi-11, Kita-19, Kita-ku, Sapporo 060-0819

\begin{abstract}
Desorption behavior of two proteins; bovine serum albumin (BSA) and egg white lysozyme (LSZ) was followed on hydroxyapatite (HAp) after $72 \mathrm{~h}$-adsorption in a static system, focusing modification effect of carbonate ion on the HAp surface. Desorbed amounts in a $5 \mathrm{mM}$ - phosphate buffer solution (PBS) showed maxima in $2 \mathrm{~h}$ for BSA and $1 \mathrm{~h}$ for LSZ. The ratio of the maximal desorbed amount to the initially adsorbed one: the desorption rate was chosen as an index of the binding strength of protein to the surface. For LSZ, the desorption rate decreased as increase of the carbonate content, indicating stronger binding. This was ascribed to the increase of the strongly-adsorption site of LSZ: the $P$ site of the $c$ face because the increase of the carbonate in HAp inhibits crystal growth along the $c$ axis and hence increases the $c$ face. On the other hand, any clear dependency was not found for BSA. However, four samples of the various carbonate contents were divided into two groups; one with the higher desorption rate with nearly full and more than full surface coverages and the other with the lower one of 0.42-0.60, assuming to be side-on (multiple-site) adsorption. This suggested that more numbers of weaker binding sites were involved in BSA adsorption on HAp with the higher desorption rate than the lower one.
\end{abstract}

(C)2009 The Ceramic Society of Japan. All rights reserved.

Key-words : Hydroxyapatite, Carbonate ion, Bovine serum albumin (BSA), Egg white lysozyme (LSZ), Adsorption and desorption properties

[Received March 25, 2009; Accepted July 16, 2009]

\section{Introduction}

Lots of reports on adsorption and desorption behavior of proteins on hydroxyapatite (HAp) have been published for investigating optimal condition of chromatographic fractionation of proteins so far. ${ }^{1)-9)}$ Recently, HAp has been paid attention as a protein drug delivery carrier. ${ }^{10), 11)}$ Therefore, researches on controlling adsorption and desorption of proteins on HAp by modifying the surface is important for design of the carrier with capability of controlled drug release.

HAp is a primary inorganic component of hard tissues such as bone and tooth, and biological HAp contains various kinds of foreign ions: $\mathrm{Na}, \mathrm{Mg}, \mathrm{K}, \mathrm{CO}_{3}{ }^{2-}$, et al., and the $\mathrm{CO}_{3}{ }^{2-}$ (carbonate ion) is the largest in amount: $3-6$ mass $\%{ }^{12)}$ The $\mathrm{CO}_{3}{ }^{2-}$ incorporated into structure of HAp was shown to decrease crystallinity of HAp, structural defects, ${ }^{13)}$ and consequently to increase solubility in acid solution, leading to biological mineralization. ${ }^{14)-18)}$ However, the effect of the carbonate ion on the surface properties: adsorption and desorption behavior of proteins has not been clear. Our interest has been especially lying how acidic and basic characters of proteins reflect adsorption and desorption behavior of the proteins on carbonate ion- and non-modified HAp. In our previous paper, ${ }^{19)}$ the adsorbed amounts of acidic bovine serum albumin (BSA) and basic egg white lysozyme (LSZ) were measured on the HAp of various carbonate contents. The adsorbed amounts of BSA and LSZ showed different dependency on the

Corresponding author: T. Kanno; E-mail: kannotr@mail.kitami-it. ac.jp carbonate content, which was ascribed to different effect of the carbonate ion on each primary adsorption site of the two proteins. In this paper, desorption behavior as well as adsorption was also examined in order to compare the binding strength between the proteins and the surface of HAp of various contents of the carbonate ion.

\section{Experimental}

2.1 Preparation and characterization of the carbonate-containing HAp

Carbonate-containing HAp was prepared as follows: 0.06 $\mathrm{mol} \cdot \mathrm{dm}^{-3}\left(\mathrm{NH}_{4}\right)_{2} \mathrm{HPO}_{4}-0.06 \mathrm{~mol} \cdot \mathrm{dm}^{-3} \mathrm{NH}_{4} \mathrm{HCO}_{3}$ aqueous solution was introduced into $0.1 \mathrm{~mol} \cdot \mathrm{dm}^{-3} \mathrm{Ca}\left(\mathrm{NO}_{3}\right)_{2} \cdot 4 \mathrm{H}_{2} \mathrm{O}$ aqueous solution at $4.5 \pm 0.5 \mathrm{~cm}^{3} \cdot \mathrm{min}^{-1}$ at $323 \pm 5 \mathrm{~K}$ under a nitrogen gas flow into the solution. The carbonate content was changed by controlling $\mathrm{pH}$ of the obtained slurry, which was aged at $\mathrm{pH} 6.0$, $7.0,8.5$ or 10.5 overnight and then dried at $373 \mathrm{~K}$ in air. The obtained powders were confirmed to have a single phase of apatite by their X-ray diffraction patterns. The qualitative and quantitative analysis of the carbonate ions were done by temperature programmed desorption technique (TPD) and fourier transform infrared spectroscopy (FT-IR). The detailed procedure and the result were described in our previous paper. ${ }^{19)}$

\subsection{Measurement of adsorption and desorption behavior of BSA and LSZ}

Bovine serum albumin (BSA) and egg white lysozyme (LSZ) were chosen as an acidic and a basic protein, respectively: the isoelectric points of BSA and LSZ were 4.7-4.9 and 11.0-11.4, 
respectively. The adsorbed amount of proteins was measured after immersing HAp powder into $0.5-3 \mathrm{mg}$-protein $\cdot \mathrm{cm}^{-3}-20$ $\mathrm{mmol} \cdot \mathrm{dm}^{-3} \mathrm{~K}_{2} \mathrm{HPO}_{4}-\mathrm{KH}_{2} \mathrm{PO}_{4}$ buffer solution $(P B S)(\mathrm{pH}=7 \pm$ $0.1)$ of $10 \mathrm{~cm}^{3}$ at $295 \mathrm{~K}$ for $72 \mathrm{~h}$ as in the previous paper. ${ }^{20)}$ The concentration of proteins in $P B S$ was measured with absorbance of $280 \mathrm{~nm}$ of the solution, and the adsorbed amount was estimated by the difference between the original concentration and the concentration in $72 \mathrm{~h}$. The adsorption isotherms showed Langmuir-type for both the proteins and the saturated-adsorbed amounts were estimated by the Langmuir plots. ${ }^{19)}$

The HAp after the adsorption experiment with $2.5 \mathrm{mg}$ protein $\cdot \mathrm{cm}^{-3}$ was used as the protein loaded-HAp sample. The sample was put in $5 \mathrm{mmol} \cdot \mathrm{dm}^{-3} P B S$ of $10 \mathrm{~cm}^{3}$ at $295 \mathrm{~K}$. Supernatant of $0.5 \mathrm{~cm}^{3}$ was taken out and the desorbed amount of the protein was measured at given times.

\section{Results and discussion}

\subsection{Adsorption behavior of BSA and LSZ on} carbonate-modified HAp.

Figure 1 shows the saturated adsorbed-amounts of BSA and LSZ versus the carbonate content, where BET specific surface areas increased with the carbonate content: ranging from 78.2 to $183.6 \mathrm{~m}^{2} / \mathrm{g} .{ }^{19)}$ The amounts of BSA decreased as the increase of the content while those of LSZ were independent of it. Crystallite size of (002) face which was estimated from XRD peak width at $2 \theta=25.6^{\circ}: D(002)$ was plotted as a function of the carbonate content in Fig. 2. $D(002)$ decreased as the increase of the content, and the curve was similar in shape to that of the adsorbed amount of BSA in Fig. 1. A primary adsorption site of BSA has been reported to be the $C$ site on the $a(b)$ face, and therefore the decreased amount of BSA was ascribed to decrease of these faces in agreement with the decrease of $D(002)$. On the contrary, the amount of LSZ was not changed by $D(002)$,

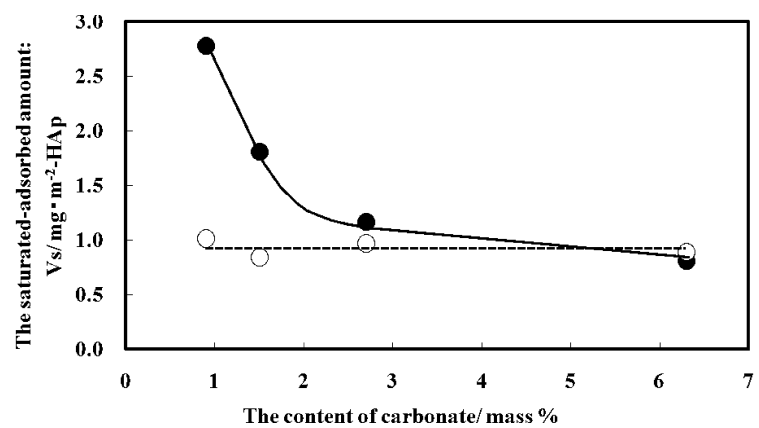

Fig. 1. Adsorbed amounts of BSA and LSZ on the HAp of various carbonate contents. BSA; $\bigcirc$ LSZ.

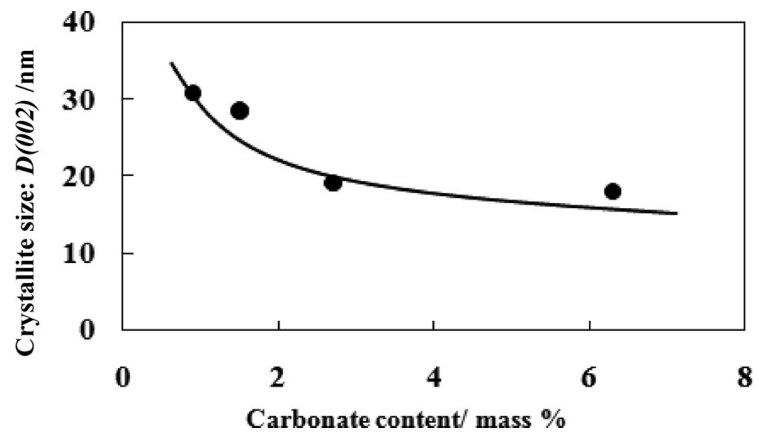

Fig. 2. $D(002)$ vs. carbonate content in HAp. although the $P$ site on the $c$ face has been reported to primarily contribute to LSZ adsorption.

$D(300)$, which reflects crystal growth along the $a(b)$ axis was not able to be compared because the XRD peak at $33.2^{\circ}$ was not resolved enough to estimate the crystallite size for the samples of higher carbonate content.

In order to compare morphological features of the samples, SEM photos were shown in Fig. 3(a) and (b), where (a) is the sample of the least carbonate content: 0.6 mass\% and (b) is one of the most content: 6.3 mass $\%$. In (a) rod-shaped particles, leading to more crystal growth along the $c$ axis and to more exposed area of the $a(b)$ face, can be seen as well as raft-shaped ones, which show large exposed area of the $c$ face. As opposed to (a), any rod-shaped particles were not found in (b), which shows less crystal growth along the $c$ axis than (a) and support the order of the $D(002)$ in Fig. 2. This morphological difference between the two samples of the higher and lower carbonate content was explained by the crystallographic change caused by introducing the carbonate ion into the structure of hydroxyapatite. Cuisinier et al. ${ }^{21)}$ suggested the presence of the carbonate ion within the lattice induced structural disorder. Therefore, the disorder must have caused less crystal growth along the $c$ axis for the sample of the higher carbonate content.

Surface coverages of BSA and LSZ were compared for endon (single-site) and side-on (multiple-site) adsorption forms in Table 1, where the molecular size of BSA is $4 \times 4 \times 14 \mathrm{~nm}$ and LSZ $3 \times 3 \times 4.5 \mathrm{~nm}^{22)}$ and therefore the projected area of BSA is assumed to be $1.6 \times 10^{-17}$ for end-on or $5.6 \times 10^{-17} \mathrm{~m}^{2} \cdot \mathrm{mol}^{-1}$ for side-on, and that of LSZ to be $9.0 \times 10^{-18}$ for end-on or $1.35 \times$ $10^{-17} \mathrm{~m}^{2} \cdot \mathrm{mol}^{-1}$ for side-on. The surface coverages of BSA ranged $0.12-0.41$ for end-on and $0.42-1.42$ for side-on. Luo and Andrade $^{23)}$ mentioned that side-on (multiple-site) binding is the most plausible adsorption form for macromolecules such as protein. Therefore, BSA is considered to cover all or almost all the surface in the high surface coverage 1.42 or 0.92 . On the contrary, the surface coverage of LSZ is nearly constant about 0.4 (a)

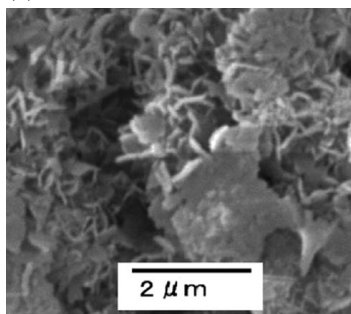

(b)

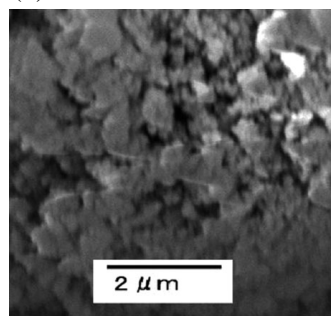

Fig. 3. SEM photos of HAp of low and high carbonate contents. (a) 0.6 mass $\%$, (b) 6.3 mass $\%$.

Table 1. Surface Coverage of BSA and LSZ of HAp of Various Carbonate Contents

\begin{tabular}{ccccccc}
\hline \multirow{2}{*}{$\begin{array}{c}\text { Carbonate content } \\
(\text { mass\% })\end{array}$} & \multicolumn{2}{c}{ BSA } & & \multicolumn{2}{c}{ LSZ } \\
\cline { 6 - 7 } 0.9 & 0.41 & 1.42 & & 0.38 & 0.58 \\
1.5 & 0.26 & 0.92 & & 0.32 & 0.48 \\
2.7 & 0.17 & 0.6 & & 0.37 & 0.55 \\
6.3 & 0.12 & 0.42 & & 0.34 & 0.51 \\
\hline
\end{tabular}




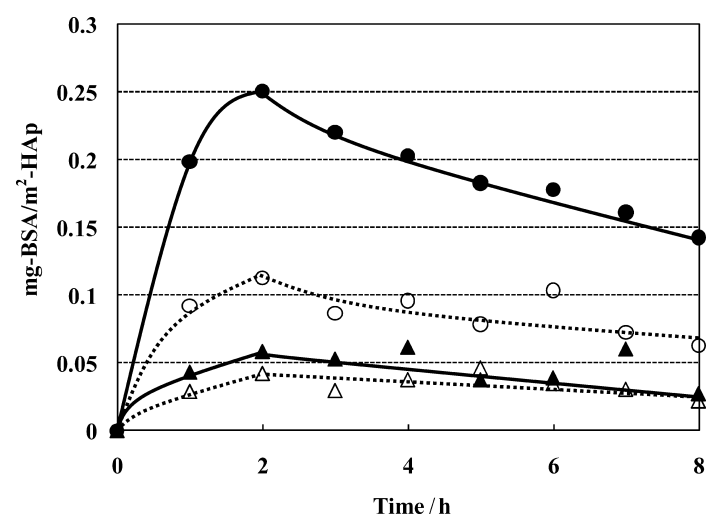

Fig. 4. Desorption behavior of BSA on HAp of various carbonate contents in $5 \mathrm{mM} \mathrm{PBS}$ at $295 \mathrm{~K}$. Carbonate content $0.9 ; \bigcirc 1.5 ; \boldsymbol{\Delta} 2.7 ; \triangle$ 6.3 mass $\%$.

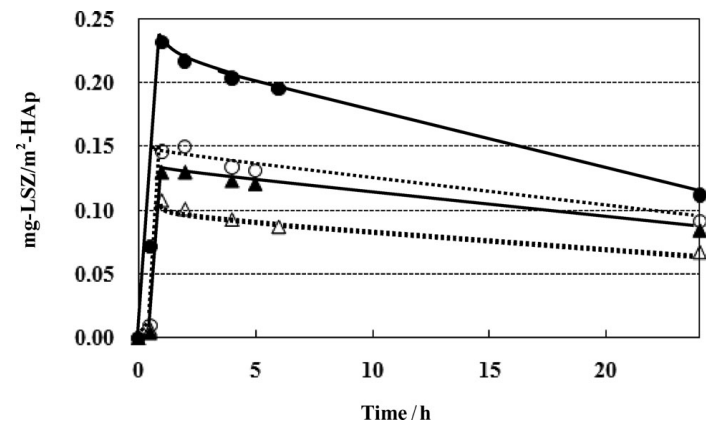

Fig. 5. Desorption behavior of LSZ on HAp of various carbonate contents in $5 \mathrm{mM} \mathrm{PBS}$ at $295 \mathrm{~K}$. Carbonate content $0.9 ; \bigcirc 1.5 ; \boldsymbol{\Delta} 2.7 ; \square$ 6.3 mass $\%$.

for end-on or 0.5 for side-on. This suggests that only half the surface contributes to LSZ adsorption for all the samples, independent of morphological features. This result seems to contradict that the primary adsorption site of LSZ is on the $c$ face mentioned before, because $D(002)$ decreased as in the increase of the carbonate content in Fig. 2. However, this contradiction can be explained by the fact that much raft-shaped area was seen even in the sample of the largest $D(002)$ as shown by Fig. 3(a).

\subsection{Desorption behavior of BSA and LSZ on car- bonate-modified HAp.}

Desorption behavior of BSA and LSZ in $5 \mathrm{mmol} \cdot \mathrm{dm}^{-3} P B S$ are shown in Figs. 4 and 5, respectively. Both the amounts increased initially and reached maxima in $3 \mathrm{~h}$ for BSA and $1 \mathrm{~h}$ for LSZ. The decreases of the amounts indicate progress of re-adsorption of the proteins onto the surface because both adsorption and desorption easily occur under our static experimental condition. Therefore, the maximum amount can be regarded as the intrinsic desorbed amount, and the ratio of this amount to the initially adsorbed one is defined as the desorption rate; $r_{\mathrm{de}}$.

The adsorbed amounts and the desorption rates for the samples of various carbonate contents were shown for BSA and LSA in Table 2, where the adsorbed amounts listed here are ones at 2.5 mg-protein $/ \mathrm{cm}^{-3}-P B S$ solution, so that the values are not the same as in Fig. 1. Here the desorption rates; $r_{\mathrm{de}}$ are focused in order to compare binding strength of the proteins to the HAp surface of various carbonate content. For BSA, clear dependency of the carbonate content on $r_{\mathrm{de}}$ is not shown as opposed to the
Table 2. Adsorbed Amount of Proteins: $\mathrm{Q}_{\mathrm{ad}}$ and the Desorption Ratio: $\mathrm{r}_{\mathrm{des}}$ of LSZ and BSA on the HAp of Various Carbonate Content

\begin{tabular}{cccccc}
\hline $\begin{array}{c}\text { Carbonate } \\
\text { content } \\
(\text { mass\% })\end{array}$ & \multicolumn{2}{c}{ BSA } & & \multicolumn{2}{c}{ LSZ } \\
\cline { 2 - 3 } \cline { 5 - 6 } & $\begin{array}{c}\mathrm{Q}_{\mathrm{ad}} \\
\left(\mathrm{mg}-\mathrm{BSA} / \mathrm{m}^{2}-\mathrm{HAp}\right)\end{array}$ & $\begin{array}{c}r_{\mathrm{de}} \\
(\%)\end{array}$ & & $\begin{array}{c}\mathrm{Q}_{\mathrm{ad}} \\
\left(\mathrm{mg}-\mathrm{LSZ} / \mathrm{m}^{2}-\mathrm{HAp}\right)\end{array}$ & $\begin{array}{c}r_{\mathrm{de}} \\
(\%)\end{array}$ \\
\hline 0.9 & 1.68 & 14.9 & & 1.02 & 22.7 \\
1.5 & 0.77 & 14.7 & & 0.77 & 19.1 \\
2.7 & 0.68 & 8.6 & & 0.85 & 15.2 \\
6.3 & 0.44 & 9.6 & & 0.80 & 13.4 \\
\hline
\end{tabular}

adsorbed amount, which changes with the carbonate content, i.e. change in crystallographic properties as suggested in the previous section. However, one thing to note is that $r_{\mathrm{de}}$ for the samples of the carbonate contents 0.9 and 1.5 mass $\%$ are larger by more than $50 \%$ than those of the contents 2.7 and 6.3 mass $\%$. This means that binding strength of BSA to the surface for the former two samples is smaller than the latter two. This idea is also supported by the result of Table 1, in which the surface coverage of BSA is 1.42 and 0.92 for side-on adsorption for the former two samples. Therefore, more numbers of weakly adsorption site is considered to be involved in BSA adsorption on HAp with high surface coverage and consequently to make $r_{\mathrm{de}}$ larger.

For LSZ, $r_{\mathrm{de}}$ decreased, i.e. stronger binding as the increase of the carbonate content. This result can be clearly explained by correlation of primary adsorption site of LSZ with crystallographic feature of the samples. As mentioned in the previous section, the primary adsorption site of LSZ has been reported to be the $P$ site of the $c$ face. $D(002)$ in Fig. 2 and SEM photos in Fig. 3 showed that the $c$ face increased as the carbonate content. This must have lead to increasing strong adsorption sites of LSZ and consequently decreasing $r_{\mathrm{de}}$.

In summary, the desorption rate; $r_{\mathrm{de}}$, which was employed as an index of binding strength of BSA and LSZ to the surface of HAp, showed different dependency of the carbonate content. It was suggested that $r_{\mathrm{de}}$ of BSA depended on its surface coverage, and that of LSZ on morphological feature of each sample. However, our experiment was done in a static system in which readsorption of protein easily occurred as mentioned before. This static system may have let the modification effect of the carbonate ion on desorption behavior vague. Therefore, a dynamic experimental system is necessary to clarify the effect more, and a new experiment with flow system, in which readsorption does not occur so much as in static one, is undertaken presently.

\section{References}

1) A. Tiselius, S. Hjertén and Ö. Levin, Archives Biochem. Biophys., 65, 132-155 (1956).

2) M. Kresak, E. C. Moreno, R. T. Zahradnik and D. I. Hay, J. Colloid Interface Sci., 59, 283-292 (1977).

3) T. Kawasaki, J. Chromatography, 151, 95-112 (1978).

4) T. Kawasaki, J. Chromatography, 157, 7-42 (1978).

5) T. Kawasaki, J. Chromatography, 515, 91-123 (1990).

6) T. Kawasaki, J. Chromatography, 544, 147-184 (1991).

7) M. J. Gorbunoff, Anal. Biochem., 136, 425-432 (1984).

8) M. J. Gorbunoff, Anal. Biochem., 136, 433-439 (1984).

9) P. Ricco, "Chromatogarphy in Biochemistry, Medicine and Environmental Research, 1" Ed. by A. Friegerio, Elsevier Scientific Co., Amsterdam (1983).

10) Japanese patent No. 2004-315299.

11) W. Paul, J. Nesamony and C. P. Sharma, J. Biomed. Mater. 
Res., 61, 660-662 (2002).

12) I. Zipkin, "The Science of Nutrition and its Application in Clinical Density" Ed. by A. E. Nizel, $2^{\text {nd }}$ Edition. Saunders Co., Philadelphia (1966).

13) F. J. G. Cuisinier, P. Steuer and J.-C. Voegel, J. Mater. Sci.: Mater. Medicine, 6, 85-89 (1995).

14) M. Okazaki, Y. Moriwaki, T. Aoba, Y. Doi and J. Takahashi, Caries Res., 15, 477-483 (1981).

15) M. Okazaki and J. Takahashi, Biomater., 20, 1073-1078 (1999).

16) G. Daculsi, R. LeGeros, M. Heughebaert and I. Barbieus, Calcif. Tissue Int., 46, 20-27 (1990).

17) R. Murugan, S. Ramakrishna and K. P. Rao, Mater. Lett., 60,
2844-2847 (2006).

18) R. Murugan and S. Ramakrishna, Acta Biomateriallia, 2, 201206 (2006).

19) T. Kanno, T. Sendai, K. Tada, J. Horiuchi and T. Akazawa, Phos. Res. Bull., 21, 25-30 (2007).

20) T. Akazawa, M. Kobayashi, T. Kanno and K. Kodaira, Chem. Lett., 25, 779-780 (1996).

21) F. J. G. Cuisinier, J.-C. Voegel and I. Mayer, J. Cryst. Growth, 125, 1-6 (1992).

22) T. Akazawa, M. Kobayashi, T. Kanno and K. Kodaira, J. Mater. Sci., 33, 1679-1957 (1998).

23) Q. Luo and J. D. Andrade, J. Colloid Interface Sci., 200, 104113 (1998). 